Research, Society and Development, v. 9, n. 8, e623985761, 2020

(CC BY 4.0) | ISSN 2525-3409 | DOI: http://dx.doi.org/10.33448/rsd-v9i8.5761

\title{
Estado trófico do reservatório Rosário localizado no município de Lavras da
}

Mangabeira-CE, semiárido nordestino

Troffic state of the rosary reservoir located in the municipality of Lavras da

Mangabeira-CE, northeast semiarid

Estado de trófico del reserva del rosario ubicado en el municipio de Lavras da

Mangabeira-CE, semiárido del noreste

Recebido: 17/06/2020 | Revisado: 18/06/2020 | Aceito: 07/07/2020 | Publicado: 21/07/2020

Hildegardo Martins Moura Filho

ORCID: https://orcid.org/0000-0001-8076-3013 Instituto Federal do Ceará, campus Juazeiro do Norte, Brasil E-mail: hildegardomartins@gmail.com

Germário Marcos Araújo

ORCID: https://orcid.org/0000-0002-3388-0265

Instituto Federal do Ceará, campus Juazeiro do Norte, Brasil

E-mail: germario@ifce.edu.br

\section{Resumo}

O Reservatório Rosário do município de Lavras da Mangabeira, está localizado na sub-bacia do Salgado, no Estado do Ceará, Brasil, é o manancial utilizado para diversos usos, entre estes o consumo humano. Conhecer a qualidade da água, principalmente no tocante ao índice de estado trófico é primordial, pois indica como está o reservatório em relação a eutrofização que por sua vez, está relacionado a possíveis lançamentos de esgotos e atividades degradadoras na área de influência do açude. Assim sendo, o presente estudo avaliou o estado trófico do reservatório, utilizando os parâmetros clorofila-a, teores de nutrientes e produção primaria como indicadores do processo de eutrofização. O monitoramento se deu durante o período de fevereiro de 2016 a maio de 2018. Para identificar o grau de trofia, utilizou-se o Índice de Estado Trófico (IET) do método de Lamparelli (2004). Para indicar o nutriente limitante, utilizou-se a razão nitrogênio/fósforo $(\mathrm{N}: \mathrm{P})$. As análises de fósforo total e clorofila-a permitiram calcular o IET médio e classificar o manancial na categoria de eutrófico. As elevadas concentrações de nutrientes confirmam a eutrofização de suas águas, mas não implicam na evolução primaria, que envolve a variação de outros fatores ambientais. Comparando os resultados obtidos das análises com a Resolução 357/05 CONAMA para água 
de classe 2, obteve-se valores fora dos padrões estabelecidos, com exceção a clorofila-a e nitrogênio total. O fósforo apresentou concentrações muito acima da legislação ambiental, o que influenciou diretamente no grau de trofia do reservatório.

Palavras chaves: Relação N:P; Índice de estado trófico; Clorofila-a; Eutrofização.

\section{Abstract}

The Rosário Reservoir in the municipality of Lavras da Mangabeira, located in the Salgado sub-basin, in the State of Ceará, Brazil, is the source used for several uses, including human consumption. Knowing the quality of the water, especially with regard to the trophic status index, is essential, as it indicates how the reservoir is in relation to eutrophication, which in turn, is related to possible releases of sewers and degrading activities in the area of influence of the weir. Therefore, the present study evaluated the trophic status of the reservoir, using the parameters chlorophyll-a, nutrient contents and primary production as indicators of the eutrophication process. Monitoring took place during the period from February 2016 to May 2018. To identify the degree of trophy, the Trophic State Index (TSI) was used through the method of Lamparelli (2004). To indicate the limiting nutrient, the nitrogen / phosphorus ratio $(\mathrm{N}$ : P) was used. The analyzes of total phosphorus and chlorophyll-a made it possible to calculate the average TSI and classify the source in the eutrophic category. The high concentrations of nutrients confirm the eutrophication of its waters, but do not imply the primary evolution, which involves the variation of other environmental factors. Comparing the results obtained from the analyzes with Resolution 357/05 CONAMA for class 2 water, values outside the established standards were obtained, with the exception of chlorophyll-a and total nitrogen. Phosphorus showed concentrations well above the environmental legislation, which directly influenced the degree of trophy in the reservoir.

Keywords: N: P ratio; Trophic status index; Chlorophyll-a; Eutrophication.

\section{Resumen}

El embalse de Rosário en el municipio de Lavras da Mangabeira, ubicado en la subcuenca del Salgado, en el estado de Ceará, Brasil, es la fuente utilizada para diversos usos, incluido el consumo humano. Conocer la calidad del agua, especialmente con respecto al índice de estado trófico, es esencial, ya que indica cómo está el depósito en relación con la eutrofización, que a su vez, está relacionado con posibles liberaciones de alcantarillas y actividades degradantes en el área de influencia del vertedero. Por lo tanto, el presente estudio evaluó el estado trófico del reservorio, utilizando los parámetros clorofila-a, contenido de nutrientes y producción 
primaria como indicadores del proceso de eutrofización. El monitoreo se llevó a cabo durante el período de febrero de 2016 a mayo de 2018. Para identificar el grado de trofeo, se utilizó el Índice de estado trófico (IET) a través del método de Lamparelli (2004). Para indicar el nutriente limitante, se usó la relación nitrógeno/fósforo $(\mathrm{N}$ : $\mathrm{P})$. Los análisis del fósforo total y la clorofila-a permitieron calcular el EIT promedio y clasificar la fuente en la categoría eutrófica. Las altas concentraciones de nutrientes confirman la eutrofización de sus aguas, pero no implican la evolución primaria, que implica la variación de otros factores ambientales. Comparando los resultados obtenidos de los análisis con la Resolución 357/05 CONAMA para agua de clase 2, se obtuvieron valores fuera de los estándares establecidos, con la excepción de clorofila-a y nitrógeno total. El fósforo mostró concentraciones muy por encima de la legislación ambiental, lo que influyó directamente en el grado de trofeo en el depósito.

Palabras clave: Relación N: P; Índice de estado trófico; Clorofila-a; Eutrofización.

\section{Introdução}

O Brasil possui um défice em saneamento básico. De acordo com os dados do Painel Saneamento Brasil (Instituto Trata Brasil, 2019), quase 100 milhões de brasileiros não tem acesso a coleta de esgoto, $54 \%$ dos esgotos do país não são tratados. Diante disto, é possível que a contaminação dos reservatórios de abastecimento seja oriunda destes esgotos não coletados ou não tratados. Um dos maiores desafios por parte dos engenheiros, técnicos e governantes, responsáveis pela da Gestão dos Recursos Hídricos, é lidar com o aumento da poluição das águas pelas atividades antrópicas nas bacias hidrográficas.

A fim de não ser nociva à saúde, a água não pode conter substâncias tóxicas e microrganismos patógenos. Portanto, faz-se necessária a realização de análises laboratoriais em vários pontos do corpo aquático para a verificação da qualidade da água, onde devem ser investigados os parâmetros físicos, químicos e microbiológicos (Cogerh, 2007).

No caso, do semiárido brasileiro, a construção de reservatórios, regionalmente chamados de açudes, foi de fundamental importância para o desenvolvimento da região. Onde são utilizados para diversas funcionalidades desde o abastecimento doméstico ao lazer. Constituindo-se, portanto, em ecossistemas de grande valor para a economia, sociedade e para a cultura local (Freitas et al., 2011).

A eutrofização tornou-se problema amplamente reconhecido de deterioração da qualidade de água em reservatórios (Ribeiro, et al., 2005). De acordo com Figueiredo (2007) 
em função da eutrofização, muitos reservatórios no mundo já perderam sua capacidade de abastecimento para as populações, para manutenção da vida aquática e para recreação. Valente (1997) entende que a eutrofização causa grande desequilíbrio ecológico, com a diminuição da qualidade e quantidade das espécies aquáticas, tornando o meio impróprio para o lazer, o qual se converte num local de disseminação de doenças.

No nordeste brasileiro, além das entradas de esgoto, outro fator que proporciona a alta concentração de nutrientes, é o acumulo de água em alguns açudes, tornando-os estagnados e submetidos à intensa evaporação. Juntamente com as escassas precipitações dessa região, o volume do reservatório diminui, gerando a concentração dos sais, dos compostos de fósforo e nitrogênio, acelerando a eutrofização e o consequente crescimento de microalgas e cianobactérias que provocam a intensa cor esverdeada (Ana, 2005).

Nas condições cearenses as fontes de nutrientes mais relevantes são: a) as descargas de esgotos domésticos; b) afluência de partículas de solos, contendo nutrientes, em decorrência de erosão hídrica; c) presença de gado, principalmente no entorno do reservatório; e d) exploração de piscicultura intensiva no espelho d'água do açude. Nas condições do semiárido a eutrofização intensifica-se pela baixa taxa de renovação da massa de água armazenada nos reservatórios, que varia a cada ano, em função da intensidade do período chuvoso (Paulino et al., 2013).

O termo eutrofização vem do grego, onde "eu" significa bom e "trophein", nutrir. Assim, eutrófico no sentido literal significa "bem nutrido", sendo, então, a eutrofização denominada como o processo que consiste no enriquecimento da concentração de nutrientes dos ecossistemas aquáticos (Toledo, et al., 1983).

Segundo Esteves (1988), os compostos estimulantes para a eutrofização são o nitrogênio e o fosforo, com sua importância como desencadeador do processo, com visto, deriva de sua atuação como fatores limitantes na produção primaria de ecossistemas, por estarem relacionados com o processo fotossintético.

Segundo Thomann \& Mueller, (1987), a razão entre as concentrações nitrogênio/fósforo (N/P) é utilizada para se estimar preliminarmente se o crescimento de algas em um lago está sendo controlado pelo fósforo ou nitrogênio para determinar qual reagente limitante.

Nutriente limitante é aquele que, sendo essencial para uma determinada população, limita seu crescimento. Em baixas concentrações do nutriente limitante o crescimento populacional é baixo. Com a elevação da concentração do nutriente limitante o crescimento populacional também aumenta. Essa situação persiste até o ponto em que a concentração 
desse nutriente passa a ser tão elevada no meio, que um outro nutriente passa a ser o novo nutriente limitante, pois de nada adianta aumentar a concentração do primeiro nutriente que a população não crescerá, pois estará limitada pela insuficiência do novo nutriente (Von Sperling, 1996).

Segundo Salas \& Martino (2001), por meio da análise de vários corpos de água em áreas tropicais e subtropicais da América do Sul e o Caribe, observaram que a limitação do crescimento do fitoplâncton nos mesmos é devida principalmente ao fósforo.

O grau trófico de um corpo hídrico é expresso pelo IET (Índice de Estado Trófico) determinado com base em concentrações de nutrientes e fitoplanctons, os mais utilizados são: fósforo e clorofila-a. São também utilizados outros parâmetros como a concentração de nitrogênio total e a transparência medida por meio do disco de Secchi. Na literatura, há diferentes equações e intervalos, que são empregados na classificação do grau de trofia (Lamparelli, 2004).

Entre os diversos modelos para cálculo do IET, destaca-se o proposto por Carlson (1977). A metodologia de Carlson, por sua simplicidade e por ter sido o pioneiro, tem sido uma das mais utilizadas para a classificação trófica de corpos lênticos e com adaptações a estruturas lóticas. No Brasil, com clima mais quentes, há importantes variações deste trabalho como nos estudos de Toledo, Jr. et al. (1983), Lamparelli (2004) e Cunha, et al. (2013).

O IET proposto por Carlson (1977), possui limitação, que é o fato de ter sido desenvolvido com base em dados de reservatórios de regiões de clima temperado, que por sua vez não se aplica em ambientes tropicais e subtropicais, por causa da diferença do metabolismo dos seres vivos. Assim, Toledo Junior et al. (1983) propuseram modificações matemáticas para se adequar a ambientes subtropicais, aplicando a análise de regressões linear aos valores das concentrações de fósforo total, ortofosfatos, clorofila-a e transparência do disco de Secchi a uma pesquisa realizada no reservatório de Barra Bonita-SP.

Lamparelli (2004), promoveu uma atualização especifica do IET em reservatórios do Estado de São Paulo, que utiliza a concentração de fósforo total e clorofila-a para determinar o grau trófico do corpo hídrico, sendo o resultado composto pelo Índice do Estado Trófico para o fósforo - IET(PT) e pelo Índice do Estado Trófico para a clorofila-a - IET(Cl-a).

O presente trabalho teve como objetivo avaliar o Índice de Estado Trófico (IET) do Reservatório Rosário no Distrito de Quitaiús, Município de Lavras da Mangabeira, Ceará Brasil, da análise do seu comportamento ao longo do tempo, utilizando os teores de nutrientes e produção primaria das concentrações dos parâmetros de nitrogênio total, fósforo total e clorofila "a". 
Os resultados também foram comparados com os limites estabelecidos na Resolução 357/05 do Conselho Nacional do Meio Ambiente - CONAMA. Pelo meio da metodologia do cálculo do IET possa ser classificado o estado trófico do reservatório em função desta classificação.

A seguir, foi descrita a metodologia utilizada para a pesquisa, que através de analises de nutrientes (fósforo e nitrogênio) juntamente com clorofila-a, utilizando cálculos de relação N:P e IET para obter a qualidade da água, cálculos estes que auxiliam para a classificação do corpo hídrico. Na sequência, são apresentados os resultados, descrevendo as concentrações dos nutrientes estudados presentes no reservatório, passando por cálculo do índice que caracteriza o estado trófico do reservatório e, consequentemente, a qualidade da água. Por fim, são apresentadas as conclusões desta pesquisa, ressaltando algumas recomendações para estudos futuros.

\section{Metodologia}

A metodologia parte da equação do índice de estado trófico (IET) de Carlson (1997) modificado por Lamparelli (2004), com a finalidade de classificar o reservatório Rosário em relação ao grau de trofia do ecossistema tanto para fosforo total como para clorofila-a, além do fator limitante proveniente da relação de fosforo total e nitrogênio total. Os métodos analíticos que foram utilizados seguiram as recomendações de APHA et al. (2005).

\subsection{Caracterização da área de estudo}

A barragem do Açude Rosário, localizado no município de Lavras da Mangabeira, no estado do Ceará, barra o rio Salgado da sub-bacia hidrográfica de mesmo nome, sendo projetada e construída no final da década de 1990 e sendo finalizada no ano de 2001 pela SRH/SOHIDRA, para as seguintes finalidades: A irrigação das localidades próximas ao açude e o abastecimento de água da cidade de Lavras da Mangabeira (Cogerh, 2011).

Esta bacia possui o rio Salgado como coletor principal. Este rio nasce na região montanhosa da Serra do Araripe no município do Crato, no estado do Ceará, e segue o sentido sul-norte até encontrar o rio Jaguaribe, próximo à cidade de Icó. Drenando uma área de $336,97 \mathrm{~km}^{2}$, a bacia do açude Rosário, pertence ao sistema hidráulico do rio Salgado (Cogerh, 2011). Na Figura 1 é mostrada a localização da cidade de Lavras da Mangabeira e do Reservatório Rosário. 
Figura 1. Mapa de localização de Lavras da Mangabeira, Estado do Ceará-Brasil e do Reservatório Rosário.
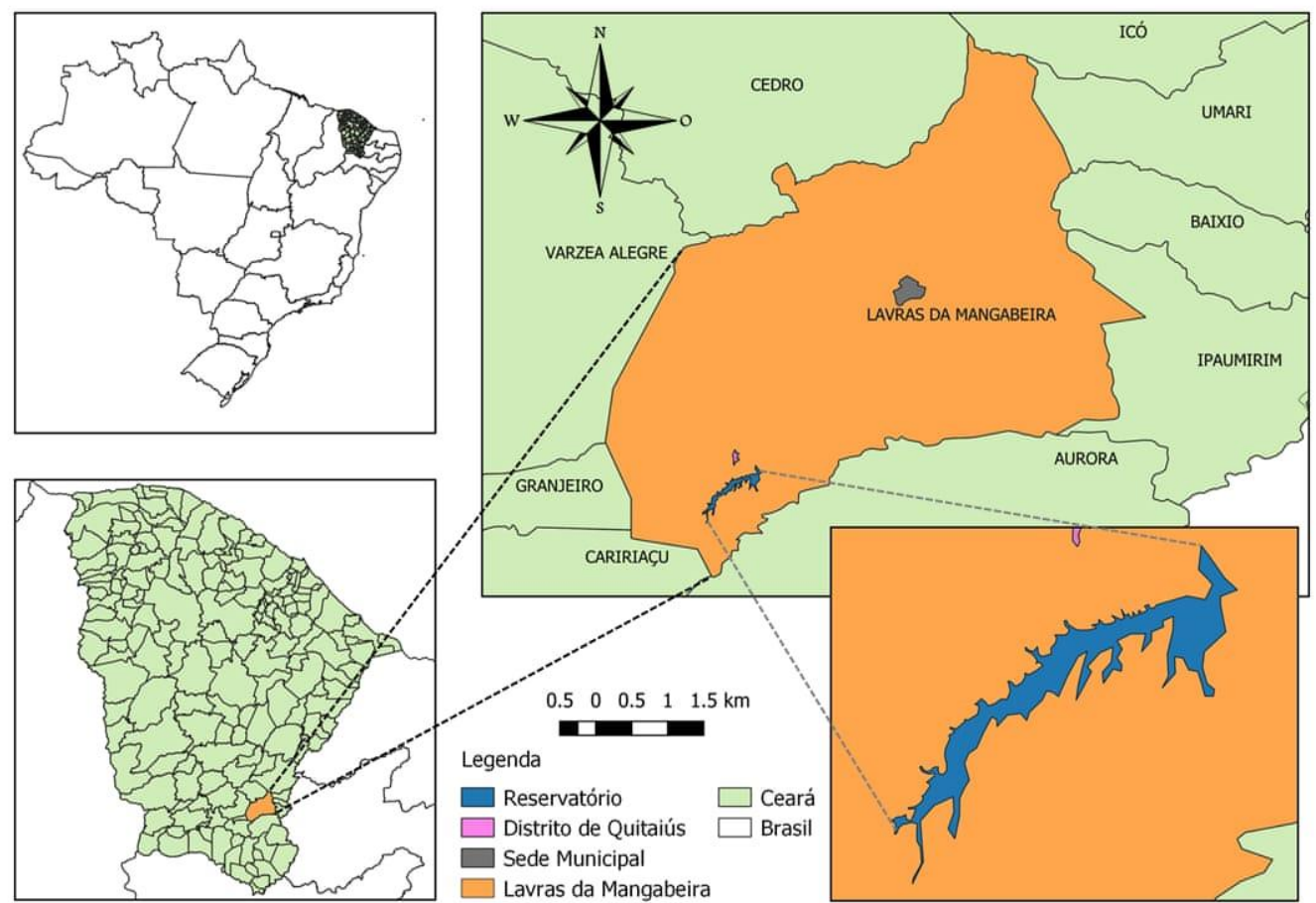

Fonte: Autores.

\subsection{Pontos amostrais e monitoramento}

Para a presente pesquisa foi demarcada 01 ponto, sendo o mesmo ponto utilizado pela COGERH para o monitoramento da qualidade da água do reservatório. Este ponto, localiza-se próximo da captação de água da CAGECE, utilizado para a estação de tratamento de água do município. Figura 2 apresenta a localização do ponto de coleta. 
Figura 2. Mapa indicando o ponto de coleta do reservatório Rosário.

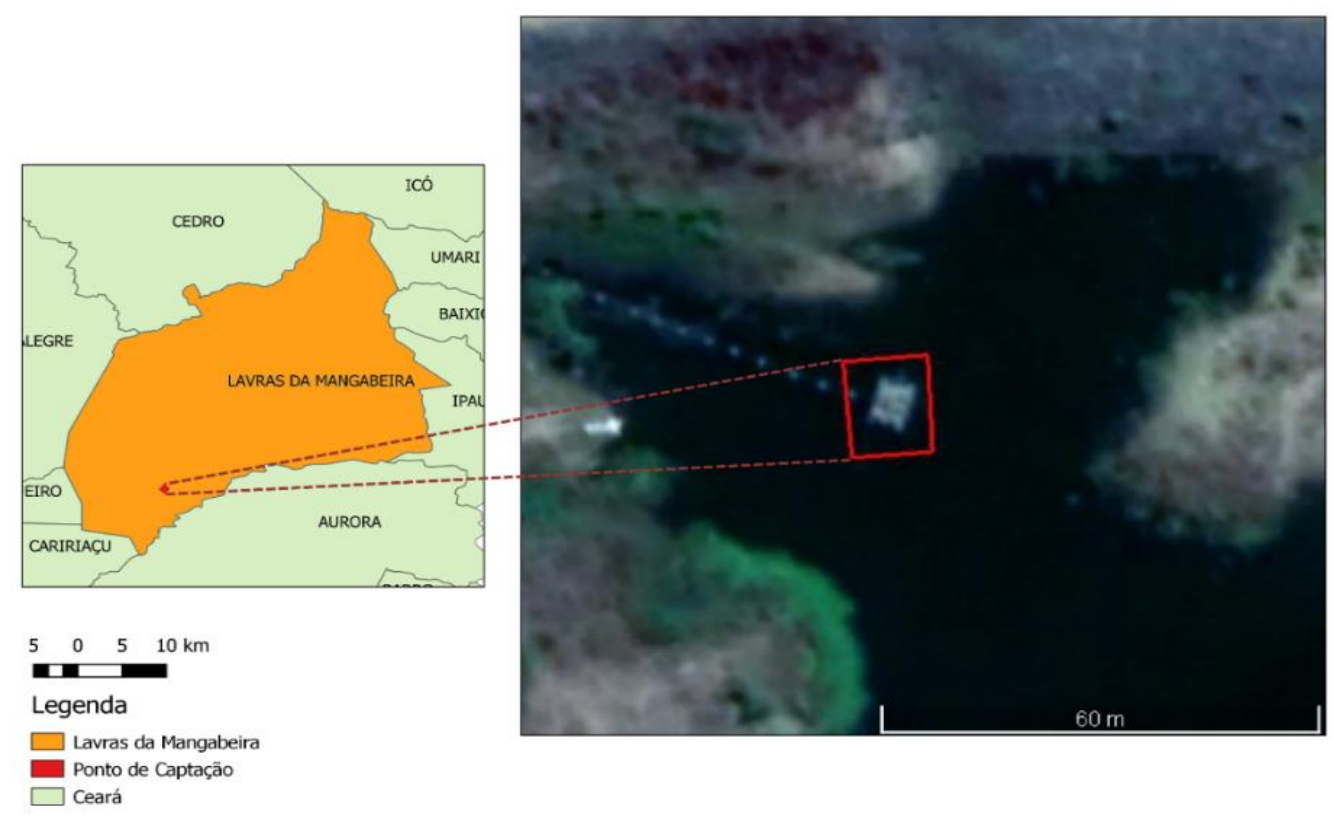

Fonte: Autores.

As amostras de água foram coletadas na superfície da coluna d'água entre o período de fevereiro de 2016 e maio de 2018, com intervalo de 3 meses. Ao todo foram analisados 30 pares de dados e logo que coletadas eram devidamente acondicionadas e encaminhadas para análise no Laboratório Integrado de Águas de Mananciais e Reservatórios - LIAMAR e Laboratório de Saneamento do Instituto Federal do Ceará - IFCE, Campus Fortaleza, para a determinação dos parâmetros.

\subsection{Parâmetros analisados e tratamento dos dados}

Os parâmetros analisados foram: a concentração de fósforo total, nitrogênio total e clorofila "a". A amostragem e os atributos avaliados seguiram a metodologia do Standard Methods for the Examination of Water and Wastewater (2005).

\subsection{Relação N:P}

Para estabelecer o fator limitante no processo de eutrofização do reservatório é usado como base a relação atômica N:P. Segundo Oliveira, (2001), as condições ideais para a 
proliferação de cianobactérias estão associadas a concentrações de nutrientes numa razão entre 20:1, que indica deficiência de fosforo, e 10:1 que indica deficiência de nitrogênio, fatores estes que podem relacionar a ocasião da eutrofização por ação antrópica. Demonstrada pela equação 1:

$$
N: P=N T / P T
$$

Equação (1)

Onde:

NT: concentração de nitrogênio total media à superfície da água em mg/L

PT: concentração de fósforo total media à superfície da água em mg/L

Sendo considerado os critérios para classificação de nutrientes apontados pela Quadro 1.

Quadro 1. Critérios para classificação do nutriente limitante.

\begin{tabular}{ll}
\hline Nutriente limitante & Critério \\
\hline Fósforo & $\mathrm{N} / \mathrm{P}>20$ \\
Nitrogênio & $\mathrm{N} / \mathrm{P}<10$ \\
\hline
\end{tabular}

Fonte: Oliveira (2001)

\section{5. Índice de Estado Trófico - IET}

Para estabelecer os critérios de qualidade, o índice de estado trófico - IET utilizado para o Reservatório Rosário, foi o de Carlson (1977) modificado por Lamparelli (2004). Com a finalidade de classificar o corpo d'água em diferentes graus de trofia, ou seja, avaliar a qualidade da água em relação a produtividade primaria do ecossistema.

Conforme Lamparelli (2004), para o cálculo do IET do fosforo total e clorofila"a", utilizou-se a equação 2 e 3 respectivamente expresso como IET $_{\mathrm{PT}}$ e IET $_{\mathrm{CL}}$; e para o IET médio que leva em consideração a média aritmética simples da soma do IET $_{\mathrm{PT}}$ e IET $_{\mathrm{CL}}$, representado na equação 4:

$$
\begin{aligned}
& I E T_{P T}=10 \times(6-((1,77-0,42 \times(\ln P T)) \ln 2)) \\
& I E T_{C L}=10 \times(6-((1,77-0,42 \times(\ln C L)) \ln 2))
\end{aligned}
$$

Equação (2)

Equação (3)

Onde:

PT: concentração de fósforo total media à superfície da água em $\mu \mathrm{g} / \mathrm{L}$;

CL: concentração de clorofila"a" media à superfície da água em $\mu \mathrm{g} / \mathrm{L}$; 
A classificação do estado trófico do reservatório foi utilizada o método de Lamparelli (2004) em comparação com o IET determinado. Conforme mostrada no Quadro 2.

Quadro 2. Classificação do estado trófico para o reservatório segundo Carlson modificado.

\begin{tabular}{lccc}
\hline \multicolumn{1}{c}{ Estado Trófico } & Ponderação & $\begin{array}{c}\text { P-total }-\mathrm{P} \\
\left(\mathrm{mg} / \mathrm{m}^{3}\right)\end{array}$ & Clorofila-a $\left(\mathrm{mg} / \mathrm{m}^{3}\right)$ \\
\hline Ultraoligotófrico & IET $\leq 47$ & $\mathrm{P} \leq 8$ & $\mathrm{Cl}$-a $\leq 1.17$ \\
Oligotrófico & $47<\mathrm{IET} \leq 52$ & $8<\mathrm{P} \leq 19$ & $1.17<\mathrm{Cl}-\mathrm{a} \leq 3.24$ \\
Mesotrófico & $52<\mathrm{IET} \leq 59$ & $19<\mathrm{P} \leq 52$ & $3.24<\mathrm{Cl}$-a $\leq 11.03$ \\
Eutrófico & $59<\mathrm{IET} \leq 63$ & $52<\mathrm{P} \leq 120$ & $11.03 \mathrm{Cl}-\mathrm{a} \leq 30.55$ \\
Supereutrófico & $63<\mathrm{IET} \leq 67$ & $120<\mathrm{P} \leq 233$ & $30.55<\mathrm{Cl}-\mathrm{a} \leq 69.05$ \\
Hiperreutrófico & IET $>67$ & $233>\mathrm{P}$ & $69.05<\mathrm{Cl}-\mathrm{a}$ \\
\hline
\end{tabular}

Fonte: Lamparelli (2004).

\section{Resultados e Discussão}

Os resultados foram comparados com a Resolução 357/05 do CONAMA, tendo em vista que no Capitulo VI, Art. 42 é relatado que "enquanto não aprovados os respectivos enquadramentos, as águas doces serão classificadas classe 2". Os parâmetros de clorofila-a, fosforo total e nitrogênio total, cujas médias e desvio padrão do reservatório estão representados conforme a Tabela 1 .

Tabela 1. Valores médios dos parâmetros e desvio padrão

\begin{tabular}{ccccc}
\hline \multirow{2}{*}{ Ponto } & \multirow{2}{*}{ Amostras } & \multicolumn{3}{c}{ Parâmetros } \\
\cline { 3 - 5 } & & P Total $(\mathrm{mgP} / \mathrm{L})$ & Clorofila-a $(\mu \mathrm{g} / \mathrm{L})$ & $\mathrm{N}$ Total $(\mathrm{mgNT} / \mathrm{L})$ \\
\hline $\mathrm{P} 1$ & 10 & $0,04(0,01)$ & $8,47(4,18)$ & $0,75(0,30)$ \\
\hline
\end{tabular}

O desvio padrão é exibido entre parêntese.

Fonte: Autores.

\subsection{Fósforo Total}

Nesta análise, foram observados dados do fósforo total no ponto de captação de água da CAGECE, na qual apresentou-se concentrações médias de $0.04 \mathrm{mg} / \mathrm{L}$. Por meio destes 
resultados, verifica-se teor de fósforo total superior ao ser comparado com a Resolução CONAMA 357/05, que por sua vez estabelece as concentrações para classe 2 no valor de 0.03 $\mathrm{mg} / \mathrm{L}$ para ambientes lênticos.

Praticamente todas as análises realizadas durante o período de estudo apresentaram valores acima da Resolução CONAMA 357/05, isso é atribuído a provável lançamento de efluente doméstico no reservatório, causando a eutrofização do manancial.

Com as variações sazonais, considerando que os períodos chuvosos foram de junho e julho de 2016, janeiro a março de 2017, junho e julho de 2017 e de janeiro a março de 2018. Observa-se que nestes meses chuvosos, não apresentaram variações de valores aos anos anteriores, isso se deve provavelmente pelo período de seca a qual o Estado estava, consequentemente o reservatório possuía volume menor de água, assim, aumentando a concentração do nutriente no manancial.

No período de estiagem no ano de 2017 houve um pico no aumento do fósforo, que no mesmo ano apresenta um valor menor dentre os demais, isso se dá a sedimentação do mesmo no reservatório e pela assimilação pelo fitoplâncton. Conforme mostra na Figura 3.

Figura 3. Distribuição espaço temporal do Fósforo Total no ponto de amostra.

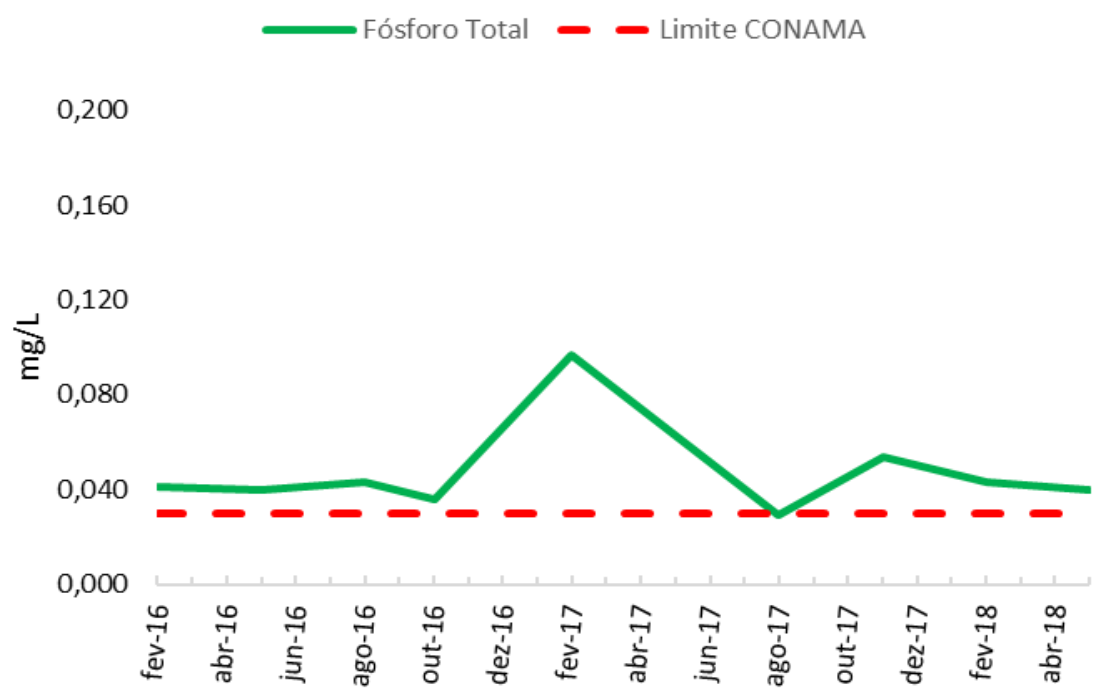

Fonte: Autores

Em estudo realizado por Toné (2016) que analisou e modelou o fósforo nos reservatórios em regiões semiáridas, apresentou que a concentração média de fósforo encontram-se acima do valor máximo permitido pela Resolução CONAMA 357/05, 
mostrando que o fósforo é o maior desafio dos reservatórios na região do semiárido, o açude do Rosário condiz com a realidade do Estado.

\subsection{Clorofila-a}

Nesta análise foram observados os dados da clorofila-a, obtidos as amostras no mesmo ponto mencionado anteriormente. A concentração média apresentou um valor de 8.47 $\mu \mathrm{g} / \mathrm{L}$, se tornando coerente ao período de escassez na qual foram estes anos de estudo, onde as clorofilas tendem a ser foto-oxidadas sob alta irradiação, proveniente de uma lâmina menor de água.

Em comparação dos resultados com a Resolução CONAMA 357/05, a qual estabelece que as concentrações de clorofila-a para a classe 2 devem ser de $30 \mu \mathrm{m} / \mathrm{L}$, observase que a amostra coletada atende à legislação ambiental em seu valor médio. Na Figura 4 pode ser observado a concentração de clorofila-a durante o período de estudo.

Figura 4. Distribuição espaço temporal de Clorofila-a no ponto de amostra.

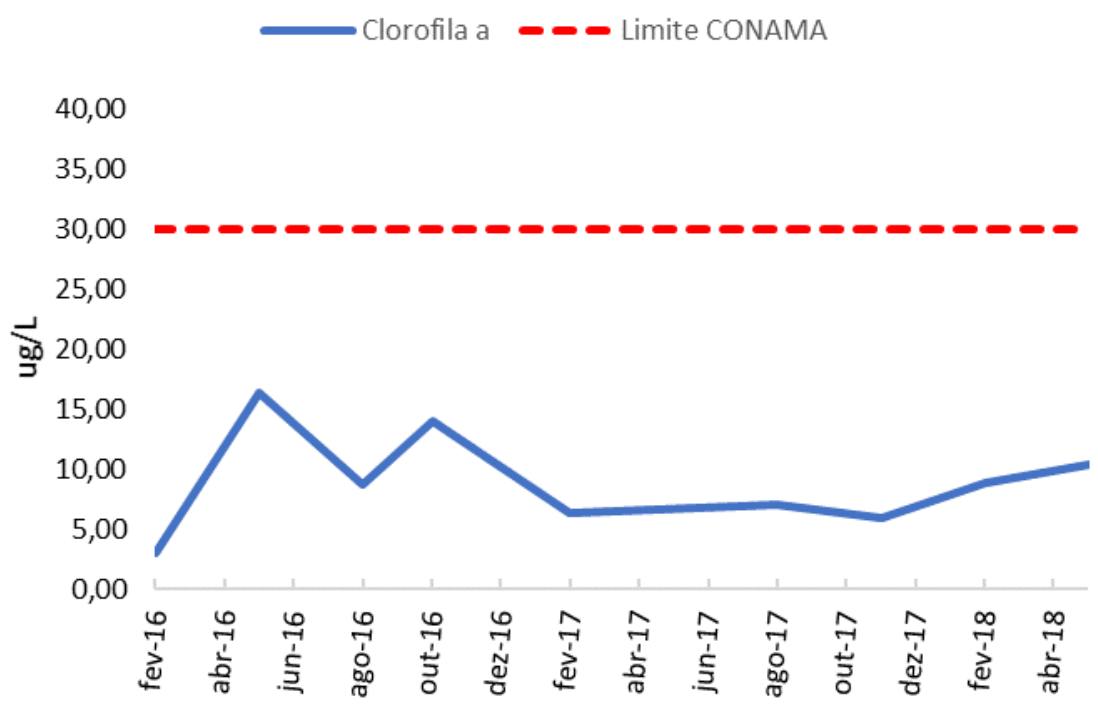

Fonte: Autores

Relacionando estes resultados com o estudo realizado por Cavalcante (2013), no açude Ayres de Souza em Sobral Ceará, os resultados foram semelhantes, com baixos valores de clorofila-a (abaixo de $30 \mu \mathrm{m} / \mathrm{L}$ ), em acordo com a legislação ambiental. Mostra-se que outras algas são predominantes no reservatório. 


\subsection{Relação N:P}

Em relação as concentrações de nitrogênio total, observa-se variações nas concentrações ao longo do tempo, com valor máximo de até $1,36 \mathrm{mgN} / \mathrm{L}$ e mínimo de até $0,31 \mathrm{mgN} / \mathrm{L}$. O desvio padrão deste parâmetro foi relativamente elevado, com valor de 0,3. Conforme informado na Tabela 2.

Tabela 2. Resultados de nitrogênio total no espaço temporal.

\begin{tabular}{cc}
\hline \multicolumn{2}{c}{ Nitrogênio total } \\
\hline Datas & P1 (mgN/L) \\
\hline fev-16 & 1,362 \\
mai-16 & 0,788 \\
ago-16 & 0,962 \\
out-16 & 0,938 \\
fev-17 & 0,862 \\
mai-17 & 0,532 \\
ago-17 & 0,475 \\
nov-17 & 0,537 \\
fev-18 & 0,763 \\
mai-18 & 0,313 \\
\hline
\end{tabular}

Fonte: Autores.

Em comparação com a Resolução CONAMA 357/05, a qual estabelece que as concentrações de nitrogênio total para classe 1 e 2 em ambientes lênticos não deve ultrapassar o valor de 1,27 mg/L, observa-se que a única amostra que não atendeu à legislação foi a amostra de fevereiro de 2016, atribui-se provavelmente ao período chuvoso na qual a região estava na época, juntamente com a manutenção dada ao ponto de captação, próximo ao ponto de coleta, assim, a provável movimentação dos sedimentos do fundo pode ter alterado as características da água, o que repercutiu na análise de nitrogênio.

Após a análise dos valores individuas de cada parâmetro analisado pela pesquisa, realizou-se a relação atômica de N:P com base em Oliveira (2004). Na Figura 5 é apresentado a disposição da relação N:P entre os períodos amostrais no reservatório Rosário. 
Figura 5. Demonstrativo da relação das Concentrações de N:P.

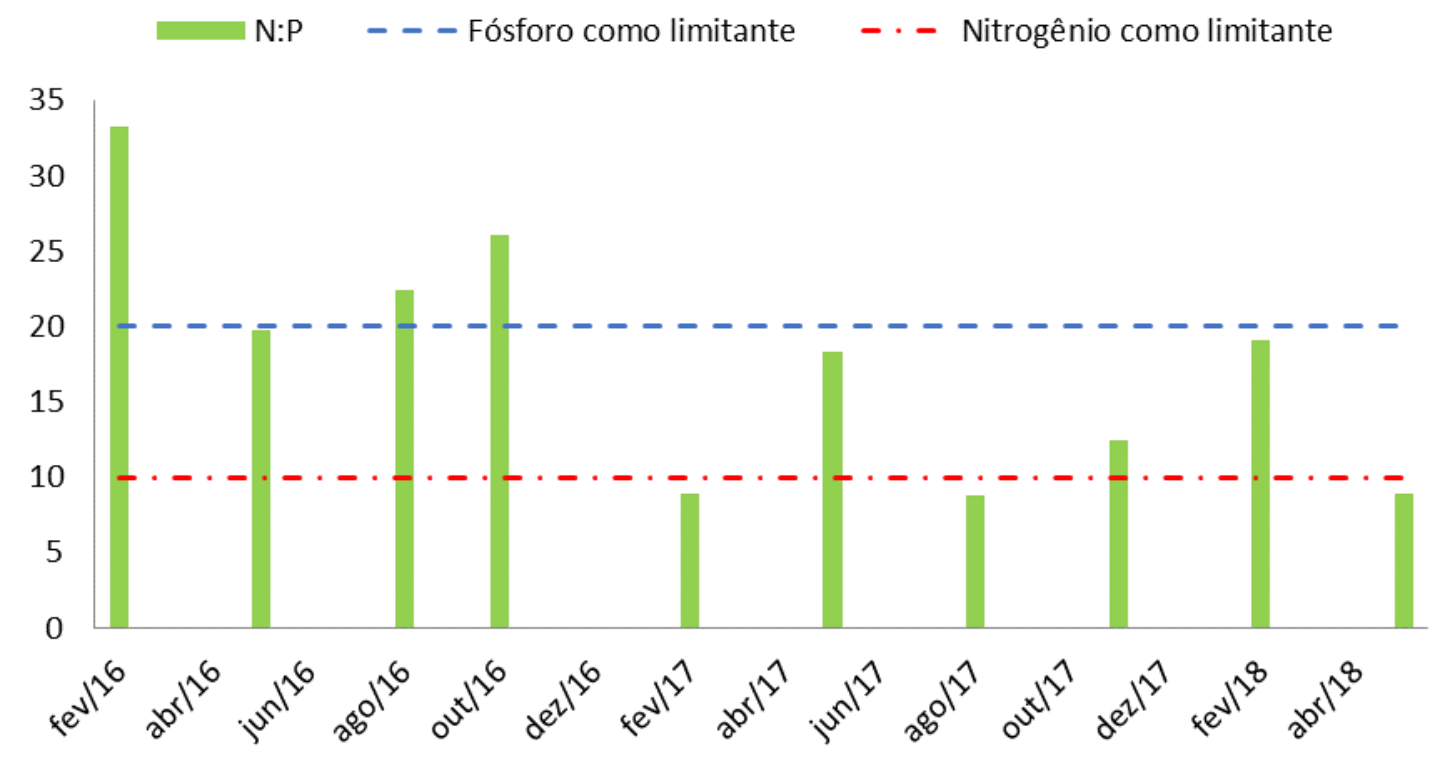

Fonte: Autores.

Considerando relações superiores de 10:1 para indicar o nitrogênio como nutriente limitante e valores superiores a 20:1, o fosforo como elemento essencial, observa-se que $30 \%$ dos valores amostrados apontam o fósforo como limitante a produção primaria, enquanto que $30 \%$ indicam o nitrogênio e os $40 \%$ restantes apontam outro aspecto ambiental pode estar influenciando no crescimento fitoplanctônico.

Ao confrontar os dados obtidos com a temporalidade, verifica-se que os períodos em que a relação atômica aponta a limitação por fósforo são períodos de contribuições pluviais e durante a escassez do ano de 2016, ocasião que não se repetiu ao longo do tempo. Em contrapartida, os períodos em que apresentam valores limitantes do nitrogênio em períodos de pouca recarga d'água no reservatório devido à falta de chuva durante estes últimos anos. Conforme apresentado, sugere-se que os aportes de fósforo neste ano de 2016, podem ser oriundos de efluentes domésticos próximo ao reservatório ou arraste de áreas agrícolas.

Outros estudos verificam a relação media N:P de 16:1 (Von Sperling, 2000), valores superiores indicam a predominância de fosforo, já valores inferiores a 16 o nitrogênio será o nutriente limitante. Sendo assim, o açude Rosário indica $60 \%$ dos dados obtidos ao longo do tempo como o fósforo o nutriente limitante, os $40 \%$ restantes indicam o nitrogênio. Admitindo estes valores, em comparação ao estudo realizado por Silva et al. (2017), que sua pesquisa se atentou na similaridade de eutrofização das águas superficiais da bacia do alto 
Jaguaribe, os reservatórios Broco e Favelas, ambos localizados no município de Tauá no Ceará, apresentaram alta relação N:P, com predominância de fósforo nos reservatórios.

Em comparação com o estudo realizado por Paulino et al. (2013), em que classificou o estado trófico para o gerenciamento de reservatórios no semiárido no Estado do Ceará, a qual avaliou 435 resultados obtidos pela Rede de Monitoramento de Qualidade de Água (RMQA), indicou que 65\% dos açudes cearenses o fósforo atuou como nutriente limitante.

\section{4. Índice de Estado Trófico - IET}

O estado trófico envolve o estabelecimento de níveis ou limites baseados no grau de intensidade do processo de eutrofização, que são: ultraoligotrófico, oligotrófico, mesotrófico, eutrófico, supereutrófico e hipereutrófico. Conforme já mencionado na Tabela 2.

Verifica-se os resultados encontrados para o IET $_{\mathrm{PT}}$ e o IET $_{\mathrm{CL}}$ (mediante as equações 2 e 3) na Figura 6.

Figura 6. Valores do IET de fósforo total e para clorofila-a em distribuição espaço temporal.

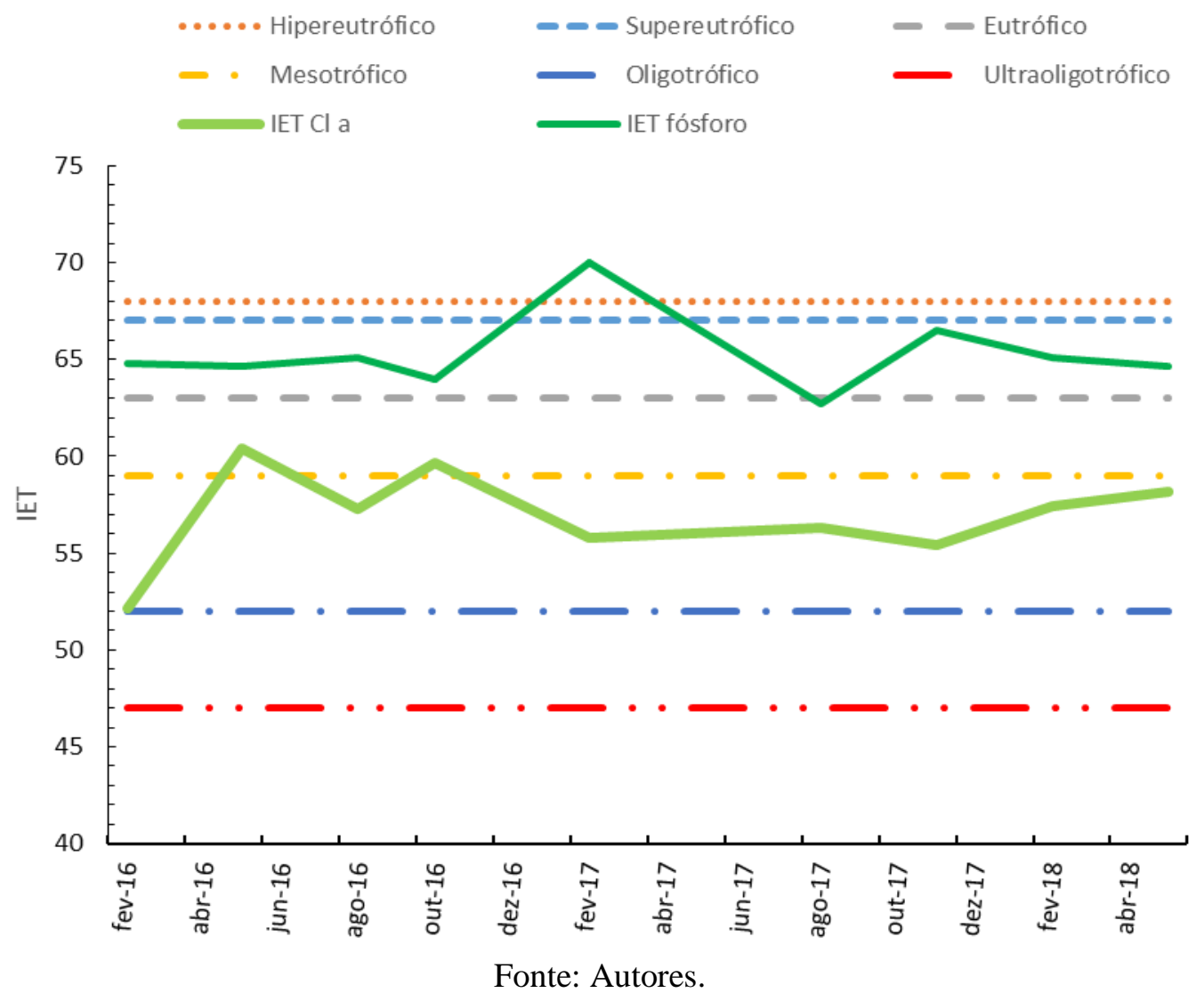


Research, Society and Development, v. 9, n. 8, e623985761, 2020

(CC BY 4.0) | ISSN 2525-3409 | DOI: http://dx.doi.org/10.33448/rsd-v9i8.5761

Por intermédio da Figura 6, é possível verificar a variação da classificação do

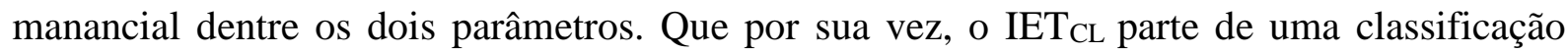
mesotrófico que caracteriza por um ecossistema com moderado desenvolvimento planctônico, chegando a ultrapassar para eutrófico ocorrendo um aumento na população de plânctons e volta para a transição de classe no mesmo ano de 2016. Já o IET PT, desde o início das análises demonstrou um ecossistema supereutrófico, chegando ao pico máximo em fevereiro de 2017 ao se classificar como hipereutrófico, que é a classificação máxima para o nível de eutrofização, mas no mesmo ano ocorre um queda, voltando ao estado supereutrófico, que se mantem até a última analise desta pesquisa.

Observa-se os resultados encontrados para o IET médio (através da equação 4) na Figura 7.

Figura 7. Valores do IET médio em distribuição espaço temporal.

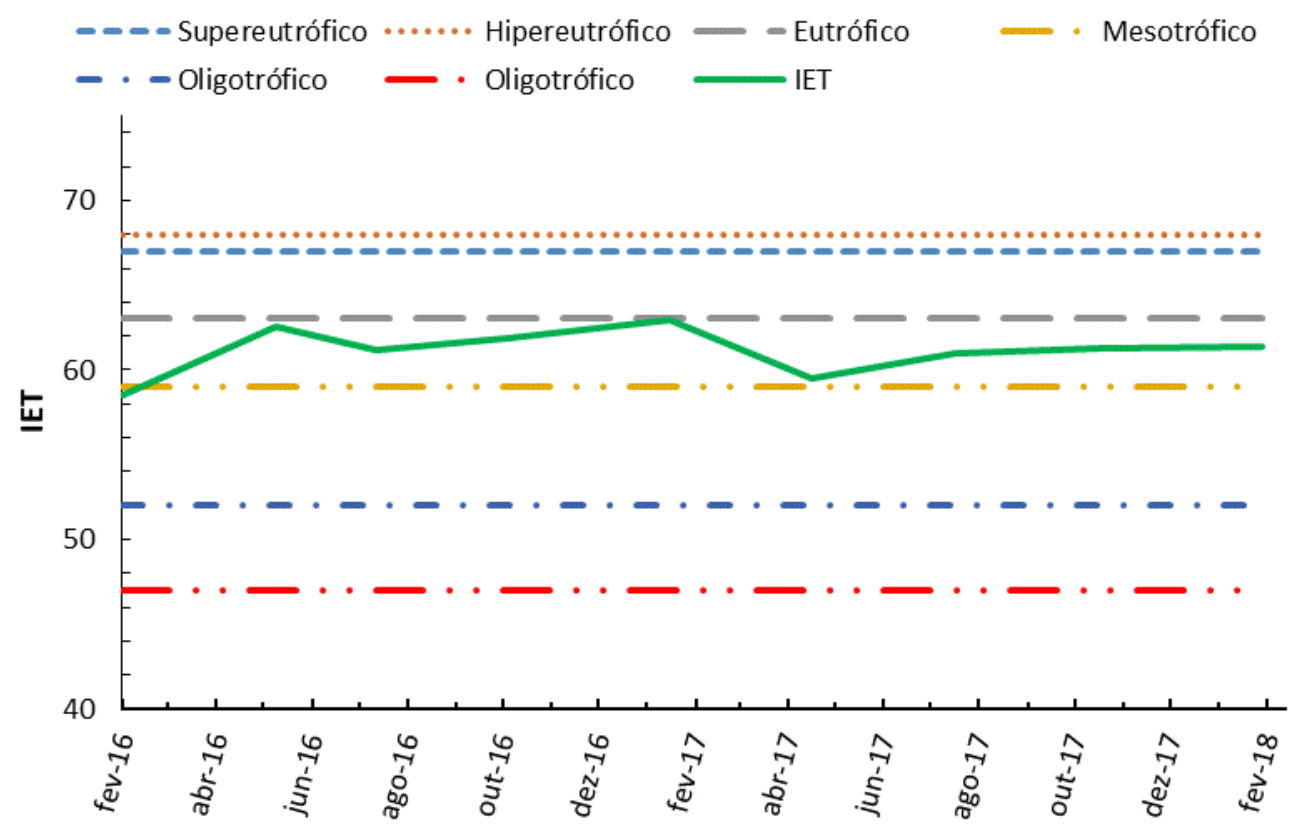

Fonte: Autores.

A oscilação dos valores de IET médio foram expressivas em maio de 2016 e fevereiro de 2017, atingindo em torno de 62,50. O comportamento dessa variação demostra o ano de 2016 como um ano característico de enriquecimento por nutrientes. A classificação do grau de trofia iniciou como mesotrófico com tendência para eutrófico, chegando a alcançar os estado estrófico em alguns momentos durante este período de análises, ou seja, um manancial 
com concentrações de nutrientes chegando no limite da qualidade da água, com tendência de alta produtividade primaria, dentre outras coisas a acelerada reciclagem de nutriente.

No geral, entre os resultados encontrados para o Índice de Estado Trófico Médio calculado, 61,09 como eutrófica. Implica que a tendência das águas do Reservatório Rosário durante o período de estudo se encontrava eutrofizado.

A tendência do Reservatório Rosário se enquadra a realidade para a maioria dos açudes do Estado do Ceará que, de acordo com avaliação realizada pela COGERH em 2020, verificou-se que 73,23\% dos 127 açudes monitorados pelo órgão se caracterizavam eutrofizados e hipereutrofizados, restando apenas 27,23\% classificados como mesotróficos e oligotróficos.

Os resultados obtidos pela pesquisa são concordantes com o estudo realizado por Pontes (2019), avaliou a variação temporal dos fatores limnológicos no reservatório Paulo Saraste no Ceará, que em sua maior parte do ano o reservatório apresentava-se no estado eutrófico, pela diminuição do volume resultante da evaporação da água no período de estiagem.

A pesquisa realizada por Cavalcante (2013), classificou o açude Ayres Souza como estrófico. A temporalidade do IET evidencia a flutuação do estado trófico de acordo com a estação do ano, mas mantendo a tendência de eutrofização das águas. Isso mostra que outros mananciais do Estado do Ceará estão sendo degradados, principalmente pela ação antrópica mediante o lançamento de efluentes e dos resíduos sólidos, comprometendo a qualidade da água nos períodos de estiagem.

\section{Considerações Finais}

O estudo demonstrou que as concentrações obtidas sugerem ao possível lançamento de substâncias eutrofizantes, podendo ser pontuais ou difusas. As difusas sendo ocasionadas pelo processo de lixiviação do solo, devido a ação da chuva. As pontuais são associadas a deficiência de operação de resíduos sólidos e de tratamento de efluentes.

Através da aplicação do IET médio foi possível classificar o reservatório na categoria de eutrófico. Pode-se afirmar que o manancial se encontra em um processo de eutrofização avançado com crescimento ao longo do tempo.

A presente pesquisa mostrou-se que o reservatório Rosário, apresenta um alto teor de fósforo, no tocante a clorofila-a os valores foram menores, isto é atribuído a cargas pontuais e 
difusas, no tocante a contaminação do reservatório e uma dispersão de fitoplâncton na coluna d'água.

As altas concentrações de nutrientes certifica a eutrofização do reservatório, mas não guia a evolução primaria, que supostamente relaciona com outras variações ambientais. Já que correlação encontrada entre fósforo e nitrogênio não apresentaram discrepância, uma vez que a clorofila-a mostrou-se em quantidade inferior à legislação ambiental.

Quando comparados os resultados obtidos dos parâmetros com a Resolução 357/05 CONAMA para águas doces classe 2 se obtiveram fora dos padrões estabelecidos, exceto a clorofila-a. O fósforo total apresentou-se em altas concentrações, ultrapassando o valor permitida pela classe na legislação ambiental, assim, afetou diretamente no grau de trofia do reservatório.

\section{Recomendações}

Para minimizar a concentração de fósforo no corpo aquático e proporcionar uma melhoria na qualidade da água do reservatório podem ser utilizadas as seguintes alternativas:

- $\quad$ Redução de interferência antrópica por lançamento de efluentes para o reservatório;

- $\quad$ Evitar plantações próximas ao leito do reservatório, principalmente se houver um uso de produtos químicos;

Verificando as ligações clandestinas e ligá-las a rede coletora de esgoto ou ao tratamento de efluente individual.

\section{Referências}

Ana, Agência Nacional de Águas (2005). Superintendência de Planejamento de Recursos Hídricos. Panorama da Qualidade das Águas Superficiais no Brasil. Caderno de Recursos Hídricos. Brasília, 1(1), 70-71.

Apha. Standard methods for the examination of water e wastewater. (2005). Washington, DC, EUA: American Public Health Association (APHA), the American Water Works Association (AWWA), and the Water Environment Federation (WEF). 21.ed. 
Carlson, R. E. (1977). Trophic state index for lakes. Limnology and Oceanography, v.22(2), 361-369.

Cavalcante, R. R. M., Oliveira, R. R. A., Barros, L. R. (2013). Evolução Temporal dos Teores de Nutrientes e Produção Primária do Açude Ayres de Souza, Sobral/CE. In: XX Simpósio Brasileiro de Recursos Hídricos, Bento Gonçalves, RS.

Cogerh - Companhia de Gestão dos Recursos Hidricos. (2011). Inventario Ambiental do Açude Rosário. Fortaleza, 12 p.

Cogerh. (2007). Parâmetros para Avaliação da Qualidade das Águas. Fortaleza, 27 .

Cogerh. (2020). Qualidade das Águas dos Açudes Monitorados. Relatório Final. Fortaleza: $\mathrm{SRH} / \mathrm{CE}$.

Conama, Conselho Nacional do Meio Ambiente (2005). Classificação dos corpos d'água. DOU, Brasília -DF.

Cunha, D. G. F, Calijuri, M. C, Lamparelli. (2013). A trophic state index for tropical/subtropical reservoirs (TSItsr). Ecological Engineering. 60(1), 126-134.

Esteves, F. de A. Fundamentos da limnologia. Rio de Janeiro: Finep, 1988. 574.

Figueirêdo, M. C. B., Teixeira, A. S., Araújo, L. F. P., Rosa, M. F., Paulino, W. D., Mota, S., Araújo, J. C. (2007). Avaliação da vulnerabilidade ambiental de reservatórios à eutrofização. Revista Engenharia Sanitária e ambiental. 12 (4) RJ. out./dez.2007.

Freitas, F. R. S., Righetto, A. M., \& Attayde, J. L. (2011). Cargas de fósforo total e material em suspensão em um reservatório do semiárido brasileiro. Oecologia australis, 15(3), 655665.

Instituto Trata Brasil. (2020). Saneamento. Principais estatísticas de esgoto no Brasil. Disponível em: http://tratabrasil.com.br/saneamento/principais-estatisticas/no-brasil/esgoto. Acesso em: 02 jun. 2020. 
Lamparelli, M. C. (2004). Grau de trofia em corpos d'água do Estado de São Paulo:

Avaliação dos métodos de monitoramento. Tese (Doutorado) - Instituto de Biociência da Universidade de São Paulo. São Paulo.

Lucas, F. H. R., Rangel Junior, A., Amorim, C. A., Costa, A. R. S., Lacerda, S.R., \& Cavalcante, F. C. (2015). Variação Temporal da Comunidade Fitoplanctônica no Reservatório Rosário/ CE. Cadernos de Cultura e Ciência (URCA), 14, 35-42.

Oliveira, M. C. B., Oliveira, M. C., \& Yunes, J. S. (2001). Cianobactérias tóxicas. O uso de marcadores moleculares para avaliar a diversidade genética. Revista Biotecnologia Ciência \& Desenvolvimento - $\mathrm{n}^{\circ} 23$ - novembro/dezembro.

Paulino, W. D., Oliveira, R. R. A., \& Freire, F. A. (2013). Classificação do estado trófico para o gerenciamento de reservatórios no semiárido: a experiência da cogerh no estado ceará. In: XX Simpósio Brasileiro de Recursos Hídricos, 2013, Bento Gonsalves-RS.

Pontes, M. M., Barros Filho, M. A. C., \& Freitas, F. R. S. (2019). Variação Temporal de Fatores Limnologicos no Reservatório Paulo Sarasate, Ceará. In: Congresso Brasileiro de Engenharia Sanitária e Ambiental, 2019, Natal. Anais Eletrônicos.

Ribeiro, L. H. L., Brandimarte, A. L. \& Kishi, R. T. (2005). Formation of the Salto Caxias Reservoir (PR) - an approach of the eutrophication process. Acta Limnologia Brasiliensia, v. 17(2) $155-165$.

Salas, H., \& Martino, P. (2001) Metodologias Simplicadas para la Evaluación de Eutroficación en Lagos Cálidos Tropicales. Programa Regional CEPIS/HPE/IOPS, Versão revisada, 52.

Silva, E. D., Neto J. R. A., Lima B. P., (2017). Similaridade de eutrofização das águas superficiais da bacia do alto Jaguaribe, Ceará. Revista Engenharia na Agricultura, 25, 336343.

Thomann, R. V., \& Mueller, J. A. (1987). Principles of Surface Water Quality Modeling and Control, Harper \& Row, Publishers, N. York. 
Toledo, A., Talarico M., Chinez, S. J, Agudo, E. G. (1983). A aplicação de modelos simplificados para a avaliação do processo de eutrofização em lagos e reservatórios tropicais. In: $12^{\circ}$ Congresso Brasileiro de Engenharia Sanitária e Ambiental, p. 1-34. Camboriú-SC, Setembro.

Toné, A. J. A. (2016). Análise e modelagem de fósforo em reservatórios localizados em regiões semiáridas. Tese de Doutorado.Universidade Federal do Ceará. Departamento de Engenharia Hidráulica e Ambiental.

Valente, J. P. S., Padilha, P. M., \& Silva, A. M. M. da. (1997). Contribuição da cidade de Botucatu - SP com nutrientes (fósforo e nitrogênio) na eutrofização da represa de Barra Bonita. Eclética Química, 22, 31-48. https://dx.doi.org/10.1590/S0100-46701997000100004

Von Sperling, E. (2000). Uso de relações limnológicas para avaliação da qualidade da água em mananciais de abastecimento. In Anais Congresso Brasileiro de Engenharia Sanitária e Ambiental.

Von Sperling. E. (1996). Introdução à Qualidade das Águas e ao Tratamento de Esgotos. Belo Horizonte: Editora do Departamento de Engenharia Sanitária, UFMG, 243p.

\section{Porcentagem de contribuição de cada autor no manuscrito}

Hildegardo Martins Moura Filho- 50\%

Germário Marcos Araújo- 50\% 